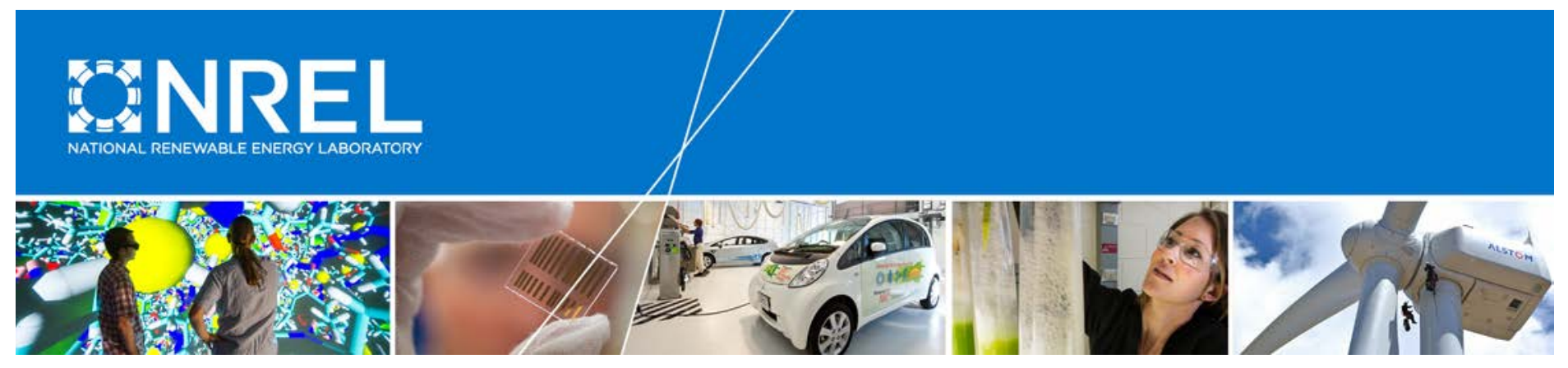

\title{
Transportation of Large Wind Components: A Permitting and Regulatory Review
}

Aaron Levine and Jeff Cook National Renewable Energy Laboratory

NREL is a national laboratory of the U.S. Department of Energy Office of Energy Efficiency \& Renewable Energy Operated by the Alliance for Sustainable Energy, LLC

This report is available at no cost from the National Renewable Energy Laboratory (NREL) at www.nrel.gov/publications.

Technical Report

NREL/TP-6A20-66998

September 2016 


\title{
Transportation of Large Wind Components: A Permitting and Regulatory Review $(A$
}

\author{
Aaron Levine and Jeff Cook \\ National Renewable Energy Laboratory
}

Prepared under Task No. EPSA.Z330

NREL is a national laboratory of the U.S. Department of Energy Office of Energy Efficiency \& Renewable Energy Operated by the Alliance for Sustainable Energy, LLC

This report is available at no cost from the National Renewable Energy Laboratory (NREL) at www.nrel.gov/publications.

National Renewable Energy Laboratory 15013 Denver West Parkway Golden, CO 80401

303-275-3000 • www.nrel.gov

\section{Technical Report}

NREL/TP-6A20-66998

September 2016

Contract No. DE-AC36-08G028308 


\section{NOTICE}

This report was prepared as an account of work sponsored by an agency of the United States government. Neither the United States government nor any agency thereof, nor any of their employees, makes any warranty, express or implied, or assumes any legal liability or responsibility for the accuracy, completeness, or usefulness of any information, apparatus, product, or process disclosed, or represents that its use would not infringe privately owned rights. Reference herein to any specific commercial product, process, or service by trade name, trademark, manufacturer, or otherwise does not necessarily constitute or imply its endorsement, recommendation, or favoring by the United States government or any agency thereof. The views and opinions of authors expressed herein do not necessarily state or reflect those of the United States government or any agency thereof.

This report is available at no cost from the National Renewable Energy Laboratory (NREL) at www.nrel.gov/publications.

Available electronically at SciTech Connect http:/www.osti.gov/scitech

Available for a processing fee to U.S. Department of Energy and its contractors, in paper, from:

U.S. Department of Energy

Office of Scientific and Technical Information

P.O. Box 62

Oak Ridge, TN 37831-0062

OSTI http://www.osti.gov

Phone: 865.576.8401

Fax: 865.576.5728

Email: reports@osti.gov

Available for sale to the public, in paper, from:

U.S. Department of Commerce

National Technical Information Service

5301 Shawnee Road

Alexandria, VA 22312

NTIS http://www.ntis.gov

Phone: 800.553 .6847 or 703.605 .6000

Fax: 703.605.6900

Email: orders@ntis.gov 


\section{Acknowledgments}

The U.S. Department of Energy's Office of Energy Policy and Systems Analysis funded this project. We thank Christopher Mone of the National Renewable Energy Laboratory and webinar participants from across the country for input and assistance on this project. Opinions represented in this report are the authors' own and do not reflect the view of the U.S. Department of Energy or the U.S. Government. This work was supported by the U.S. Department of Energy under the contract number EPSAz330. 


\section{Executive Summary}

This report summarizes permitting and regulatory issues associated with transporting wind turbine blades, towers, and nacelles as well as large transformers. These "wind components" are commonly categorized as oversized and/or overweight (OSOW) and require specific permit approvals from state and local jurisdictions. The report was developed based on a recommendation in the U.S. Department of Energy's 2015 Quadrennial Energy Review on logistical requirements for the transportation of "oversized or high-consequence energy materials, equipment, and components."

State regulations vary widely in permitting thresholds (i.e., dimensional limits) as well as requirements for civilian or police escort vehicles, time and day of travel restrictions, process for route development, and use of web-based permitting systems. Various industry groups have sought to harmonize OSOW permitting thresholds and requirements to simplify the process for transporting OSOW loads like wind components across states and regions. However, to date, no uniform standard for all Lower 48 states exists.

Challenges related to transporting wind components are not limited to issues surrounding interstate travel and harmonization. OSOW hurdles also exist for intrastate travel and coordination among industry, state permitting authorities, and local jurisdictions. In addition, complications associated with route development and required route changes can cause significant delays in obtaining OSOW permits if plans for them are not carefully made.

Various states and regions of the United States (through multi-state partnerships) have developed and employed best practices to overcome permitting hurdles, including infrastructure improvements on state bridges and highways, regional permitting coalitions, online permitting systems, and other strategies to expedite permit processing and route approval.

This report includes:

- A summary of current OSOW transportation regulations at the federal and state levels

- A [discussion/overview/etc.] of the issues and hurdles for transporting OSOW wind components

- Best practices currently employed by individual states or regions of the United States to streamline the regulatory process for transporting OSOW wind components. 


\section{List of Acronyms}

GAO

HOOCS

OSOW

NREL
Government Accountability Office

Highway Oversize/Overweight Credentialing System oversized and overweight

National Renewable Energy Laboratory 


\section{Table of Contents}

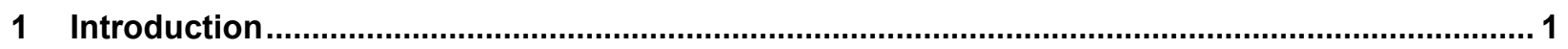

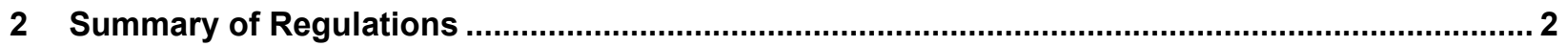

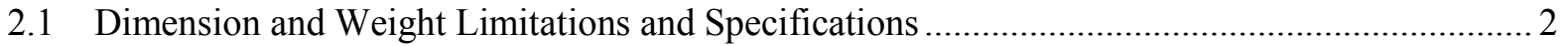

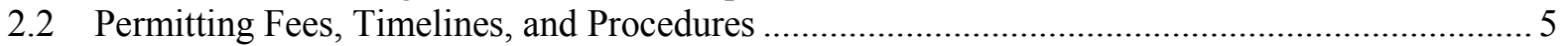

2.3 Routing Development, Survey, and Notification Procedures ................................................. 6

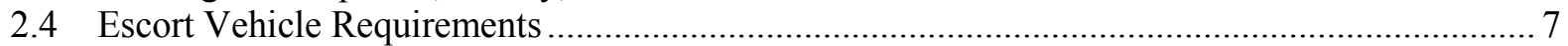

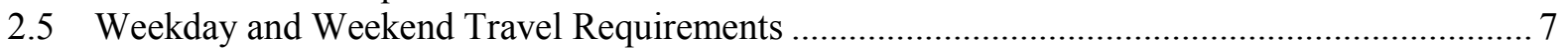

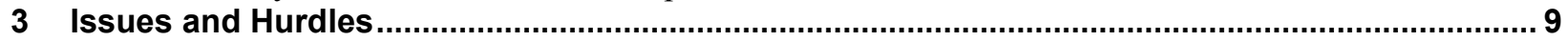

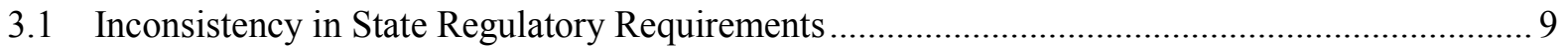

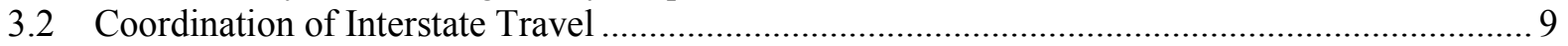

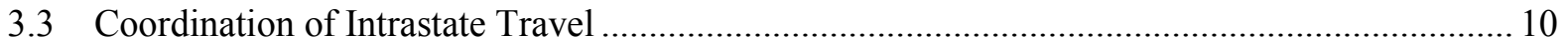

3.4 Permit Delays and Complications Associated with Route Development and Changes .............. 10

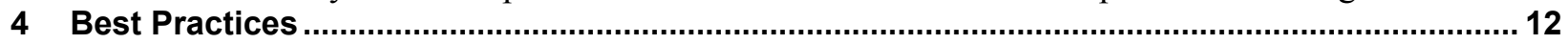

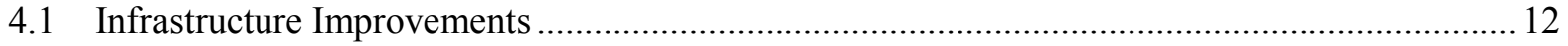

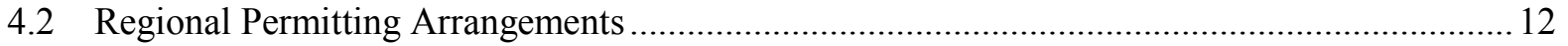

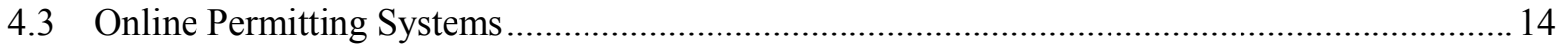

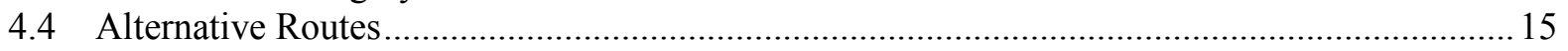

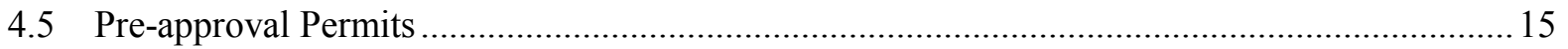

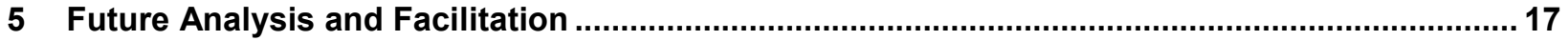

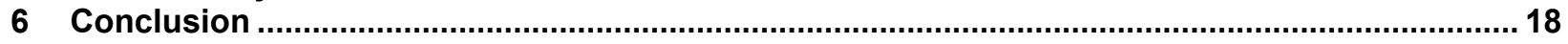

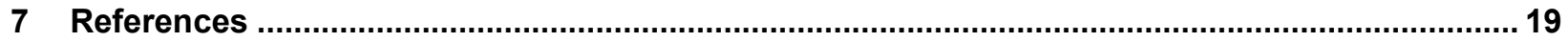




\section{List of Figures}

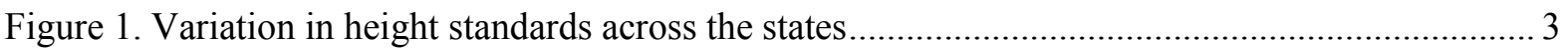

Figure 2. Variation in state length requirements for OSOW load designation...................................... 4

Figure 3. Variation in state width requirements for OSOW load designation..................................... 4

Figure 4. Variation in permitting fees across the states................................................................. 5

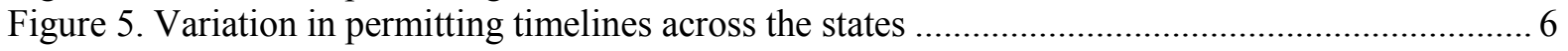

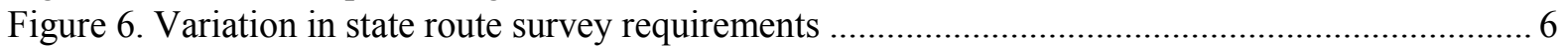

Figure 7. Number of states that may require at least one law enforcement escort for

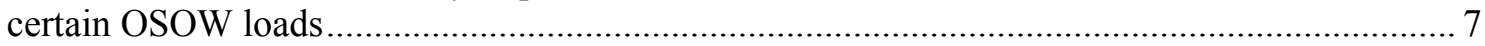

Figure 8. Number of states that allow 24-hour weekday travel for at least some OSOW loads ............ 8

Figure 9. Number of states that allow 24-hour weekend travel for at least some OSOW loads ........... 8

Figure 10. States that participate in a regional permitting agreement .............................................. 13

\section{List of Tables}

Table 1. Common 2 MW Wind Turbine Specifications. 


\section{Introduction}

The first installment of the U.S. Department of Energy Quadrennial Energy Review (DOE 2015) ${ }^{1}$ identified system vulnerabilities and steps for modernization of the energy infrastructure of the United States, with a focus on energy transmission, storage, and distribution. One important recommendation from the report was for an assessment of logistical and infrastructure requirements for the transportation of "oversized or high-consequence energy materials, equipment, and components." Specifically, an assessment of the logistical and infrastructure requirements for transporting oversized and/or overweight (OSOW) loads, such as wind turbine blades, towers, and nacelles as well as large transformers.

In furtherance of this recommendation, the U.S. Department of Energy Office of Energy Policy and Systems Analysis requested that the National Renewable Energy Laboratory (NREL) hold a stakeholder workshop to understand the range of relevant permitting issues and thereafter conduct a permitting/regulatory analysis of the relevant issues. The goal of this analysis is to assess the status and opportunity for improvement of regulatory practices necessary for large wind components from current and potential manufacturing facilities to the end-use markets.

On February 24, 2016, NREL held the stakeholder workshop in the form of a webinar. The workshop focused on permitting requirements and efforts to harmonize the permitting and regulatory process for transporting large wind components. A group of diverse stakeholders from across the country ${ }^{2}$ participated in the webinar. The stakeholders discussed current issues and hurdles within the regulatory process as well as activities that states or regions of the United States have completed to streamline or process OSOW permits more efficiently. The stakeholder webinar provided greater clarity and focus on assessing the permitting and regulatory requirements and issues for this analysis.

This report summarizes NREL's analysis, including the:

- Current regulations for transporting OSOW loads on federal and state highways, including general dimension and weight limitations, permitting timelines, route development, escort requirements, and day of week limitations

- Current issues and hurdles related to permitting OSOW loads, including interstate and intrastate coordination, permit delays and complications, inconsistency in state regulatory requirements, and data required for permitting

- Activities undertaken in states or regions of the United States to streamline or process OSOW loads more efficiently, including infrastructure improvements, multi-state permits, online permitting systems, the development of alternative routes, and preapproval permits.

\footnotetext{
${ }^{1}$ For more information about the Quadrennial Energy Review, see http://energy.gov/epsa/quadrennial-energyreview-qer.

${ }^{2}$ Attendees of the webinar included state regulators from Colorado, Delaware, Florida, Massachusetts, Minnesota, Missouri, Nebraska, New York, Pennsylvania, Texas, and Wisconsin, as well as manufacturers, logistics consultants, transportation companies, and representatives of the U.S. Department of Energy Office of Energy Policy and Systems Analysis.
} 


\section{Summary of Regulations}

To ensure the safe and efficient travel of OSOW loads on public roadways, the Lower 48 states have imposed regulations requiring approval and emplacing other stipulations. For example, states have clarified the types of vehicles that must submit an OSOW load permit, what if any escort vehicle is required, the routes OSOW vehicles can take, and time restrictions on when these vehicles can travel.

Given the significant size and weight associated with large wind components, including turbine blades, towers, and nacelles (Table 1), vehicles transporting these components are often classified as OSOW loads.

Table 1. Common 2-MW Wind Turbine Specifications ${ }^{a b}$

\begin{tabular}{lcccc}
\hline Wind Component & Length (feet) & Height (feet) & Weight (pounds) & Width (feet) \\
\hline Blade & $161-177$ & - & 154,300 & - \\
Nacelle & 34 & 13 & 176,370 & 12 \\
Tower & $263-410$ & $14-15$ & - & $14-15$ \\
\hline
\end{tabular}

a Dimensions are based on three Vestas 2-MW turbine specifications: V100-1.8/2.0 MW, which is available at https://www.vestas.com/en/products/turbines/v100-18 $20 \mathrm{mw}$; V100-2.0 MW, which is available at https://www.vestas.com/en/products/turbines/v100-2 $0 \mathrm{mw}$; and V110-2.0 MW, which is available at https://www.vestas.com/en/products/turbines/v110-2 $0 \mathrm{mw}$. Tower width/height and nacelle weight are from Zayas et al. (2015).

$\mathrm{b}$ The height of the wind tower is reflective of the height when laid on its side for transport; this measure is the diameter of the wind tower.

Though all states have OSOW load regulations, these regulations are inconsistent, making it difficult to transport OSOW loads such as wind components across state lines. A recent report from the Government Accountability Office (GAO) revealed some of the variation across these regulations (GAO 2015). This section offers a more in-depth picture of the regulatory variation across the Lower 48 states. ${ }^{3}$

\subsection{Dimension and Weight Limitations and Specifications}

Though states are at the forefront of regulating the transportation of OSOW loads, the federal government does play a role in regulating the industry. The federal government sets maximum width and weight requirements for approximately $0.5 \%$ (223,000 miles) of the over four million public highway and road miles in the United States (GAO 2015). For the federally regulated highways, vehicles may not weigh more than 80,000 pounds or be wider than 8 feet 6 inches without a permit. The federal government does not set a maximum height requirement, while it does set a minimum length requirement for a semi-trailer at 48 feet.

\footnotetext{
${ }^{3}$ Alaska and Hawaii are omitted, given the focus of this memorandum on devising best practices for interstate transport of wind turbine components.
} 
States may set their own standards on roads where the federal standards do not apply, but the vast majority of states have adopted the maximum width and weight requirements set forth by the federal government. All but one state, Michigan, have adopted the federal government's width requirement, while 45 states have adopted the weight requirement; Maine, Washington, and Wyoming have set higher maximum weight limits.

In contrast, states have set their own trailer length standards, with a majority of states (36) setting length standards at 53 feet. Though the federal government has not established height regulations, the states do have height requirements ranging from 13 feet 6 inches to 14 feet 6 inches, with most states at the lower end of the range (Figure 1).

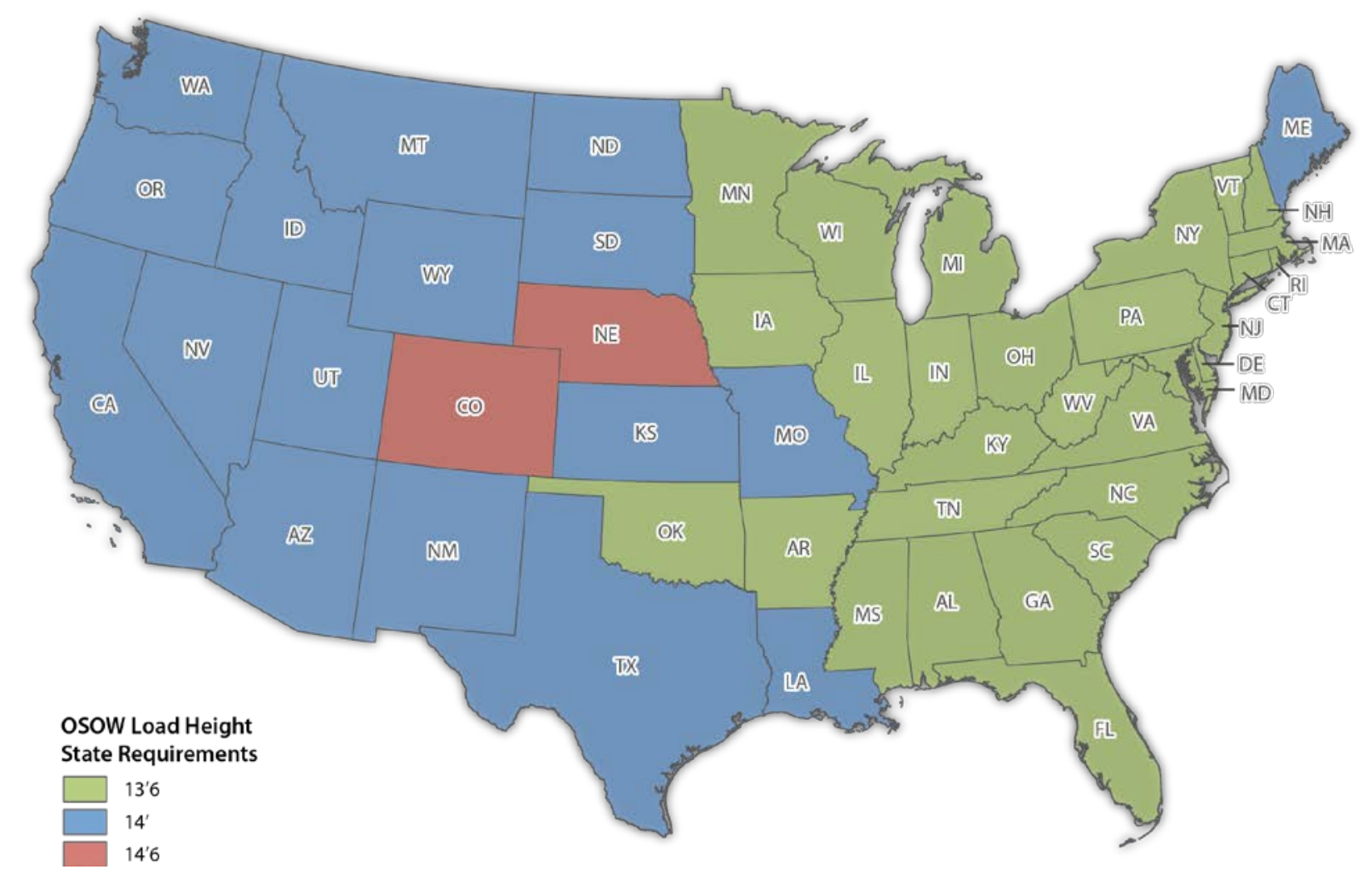

Figure 1. Variation in height standards across the states

Any loads that exceed a given state's dimensional and weight requirements qualify as OSOW loads in that state, and they may be subject to additional permitting, escort, and travel requirements. The thresholds to qualify as an OSOW load vary significantly across the states. Similar variation exists within state width and height designations as reflected in Figure 2 and Figure 3. 


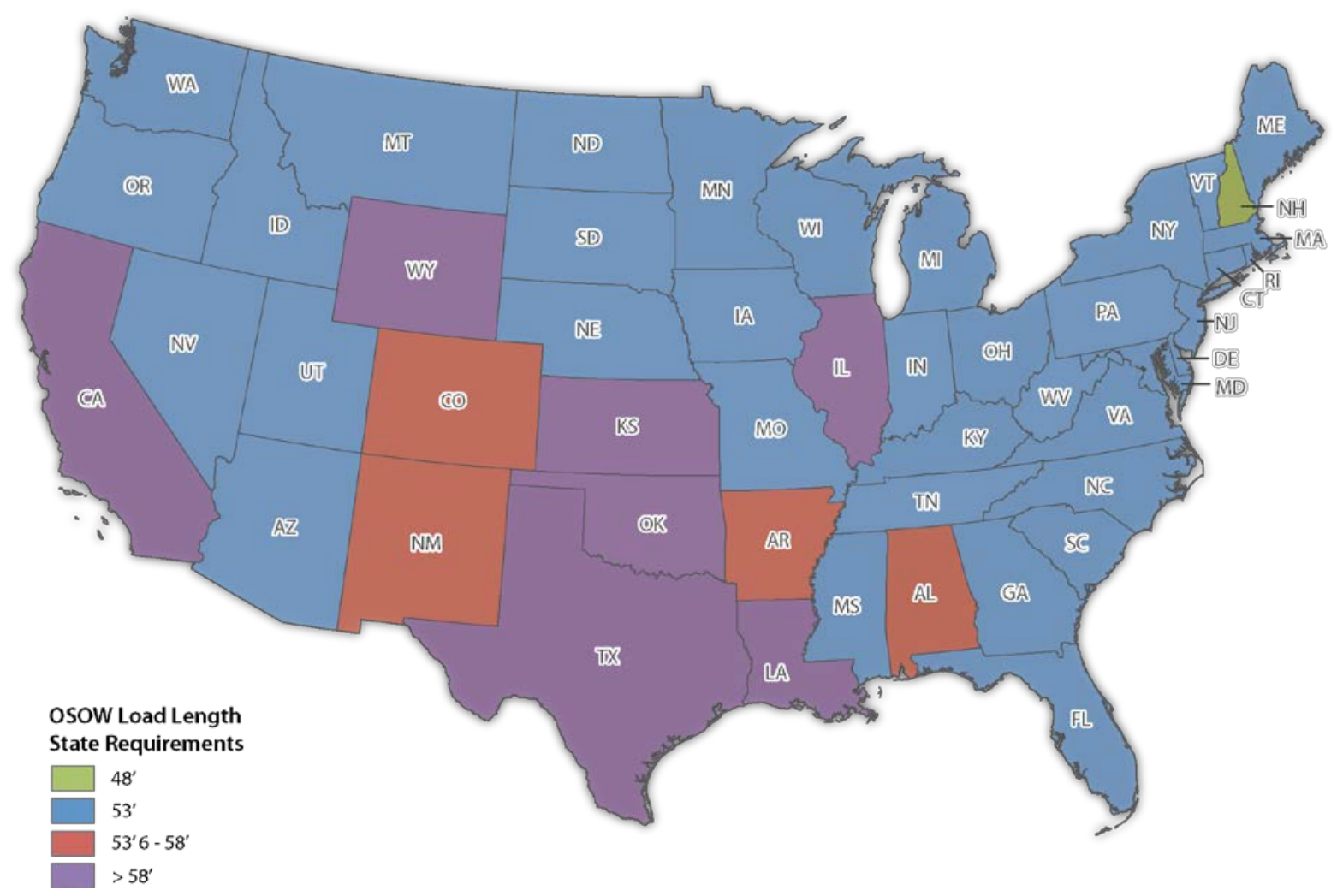

Figure 2. Variation in state length requirements for OSOW load designation

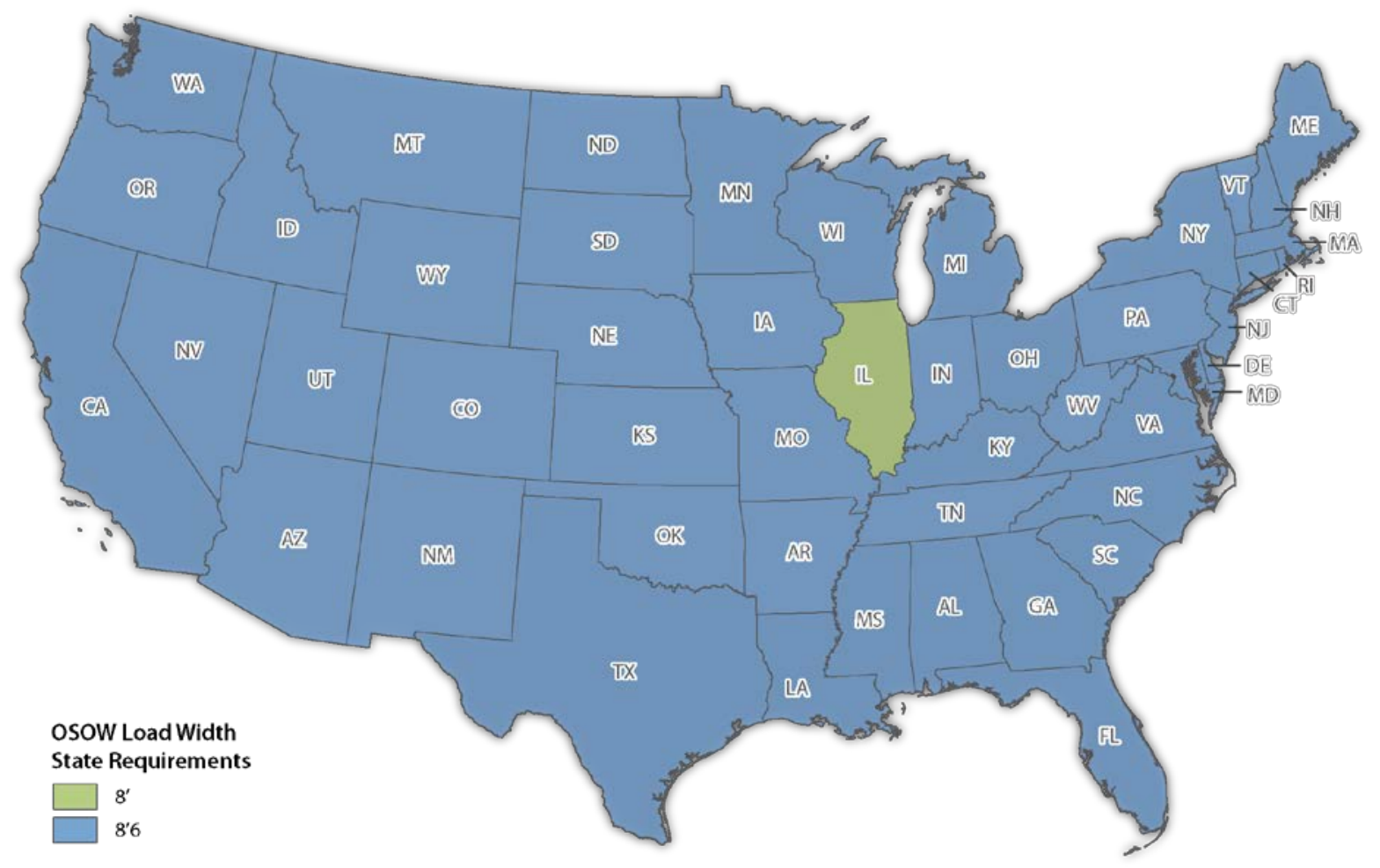

Figure 3. Variation in state width requirements for OSOW load designation 


\subsection{Permitting Fees, Timelines, and Procedures}

Once a load exceeds one of the dimension or weight limitations, the carrier must obtain a permit to travel on roads and highways under the state's control. Most frequently, states issue single-trip permits to OSOW loads; to begin the permitting process, carriers are required to pay a fee that ranges from less than $\$ 10$ to more than $\$ 60$ (Figure 4).

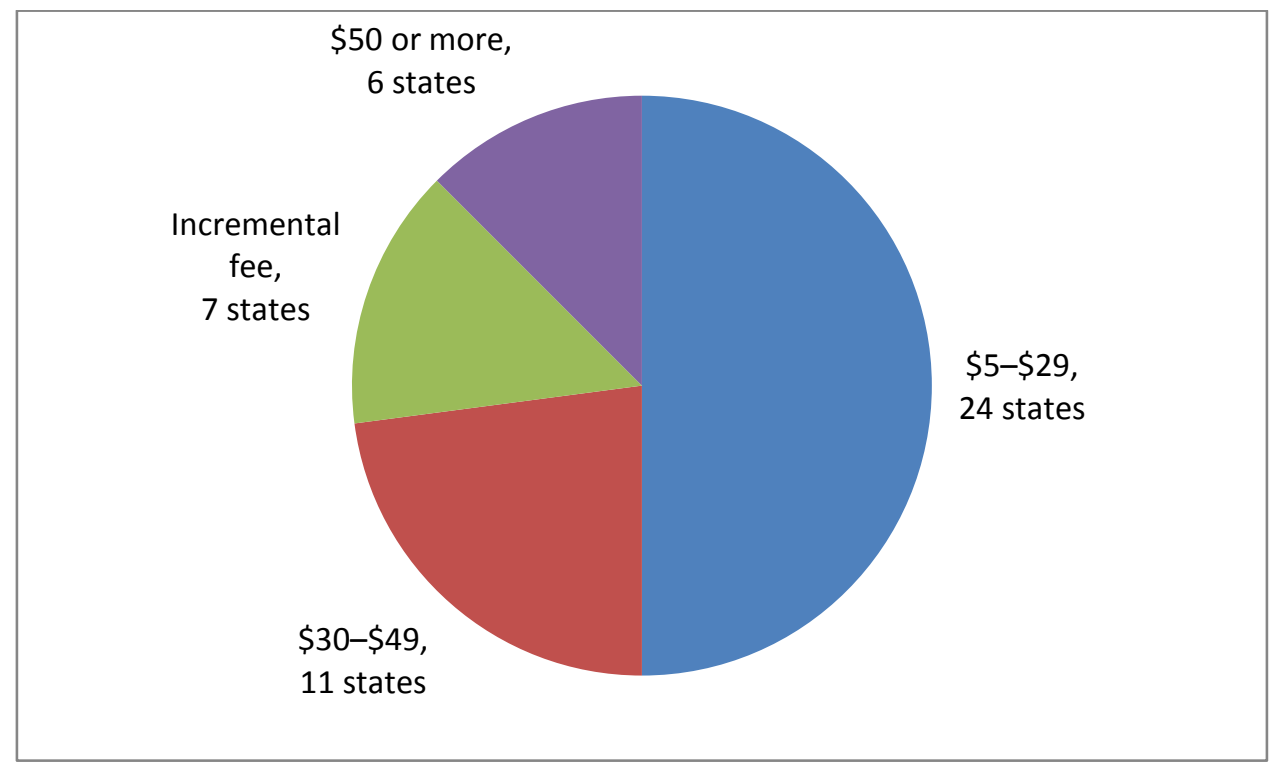

Figure 4. Variation in permitting fees across the states

Also, states process these permits on different timescales. For example, some states process permits in less than one hour, while others take two or more days. Despite this range, most states tend to process a permit within a day or two days of receiving it.

Once a state issues a single-trip permit, expiration dates vary, but most frequently, a permit lasts three days (Figure 5). Once a permit is active, 38 states allow permit extensions and 35 states allow revisions. 


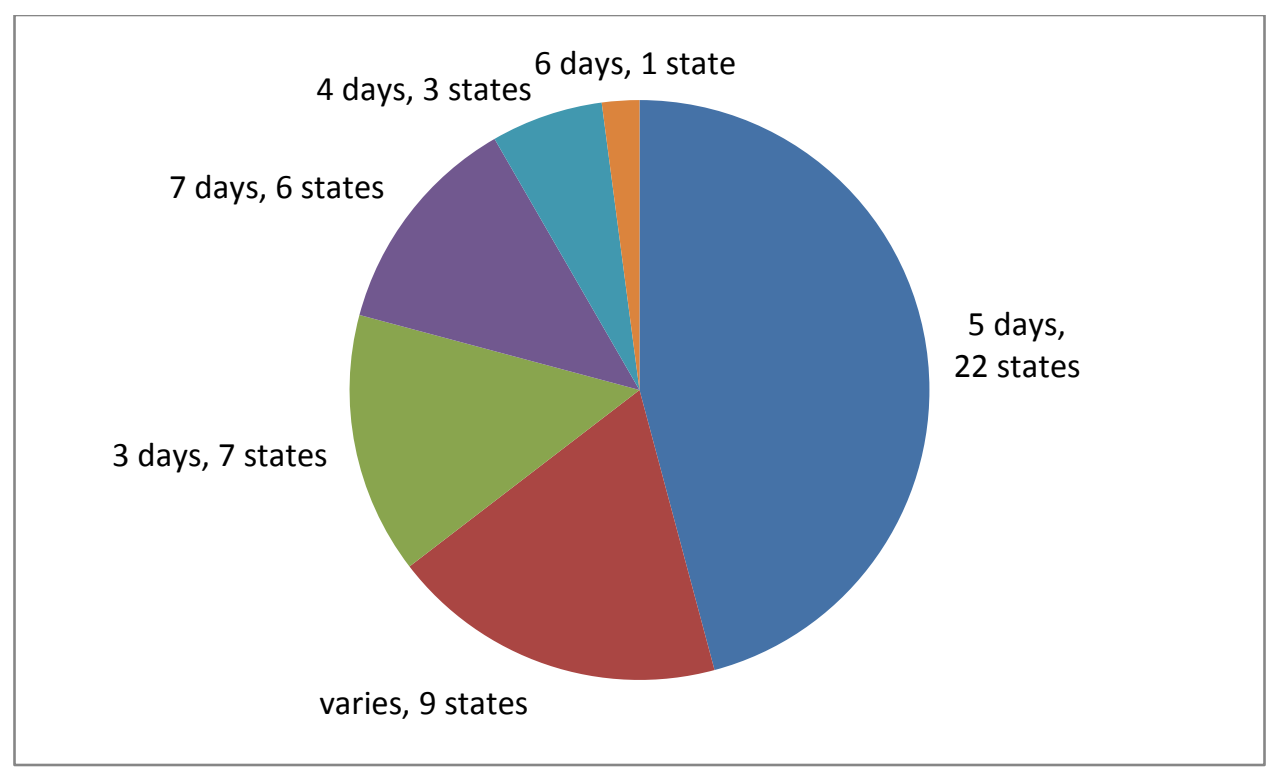

Figure 5. Variation in permitting timelines across the states

\subsection{Routing Development, Survey, and Notification Procedures}

During the permitting process, states work with carriers to determine acceptable routes and route alternatives for OSOW loads to navigate the state. These approaches can vary from employing automated route-generating software to determine the route using surveys where the carrier is required to physically drive the route. Currently, 23 states employ automated route-generating software, while 25 do not. Regardless of the method to generate a route, some states still require a route survey prior to travel, depending on the height of a carrier's load (Figure 6).

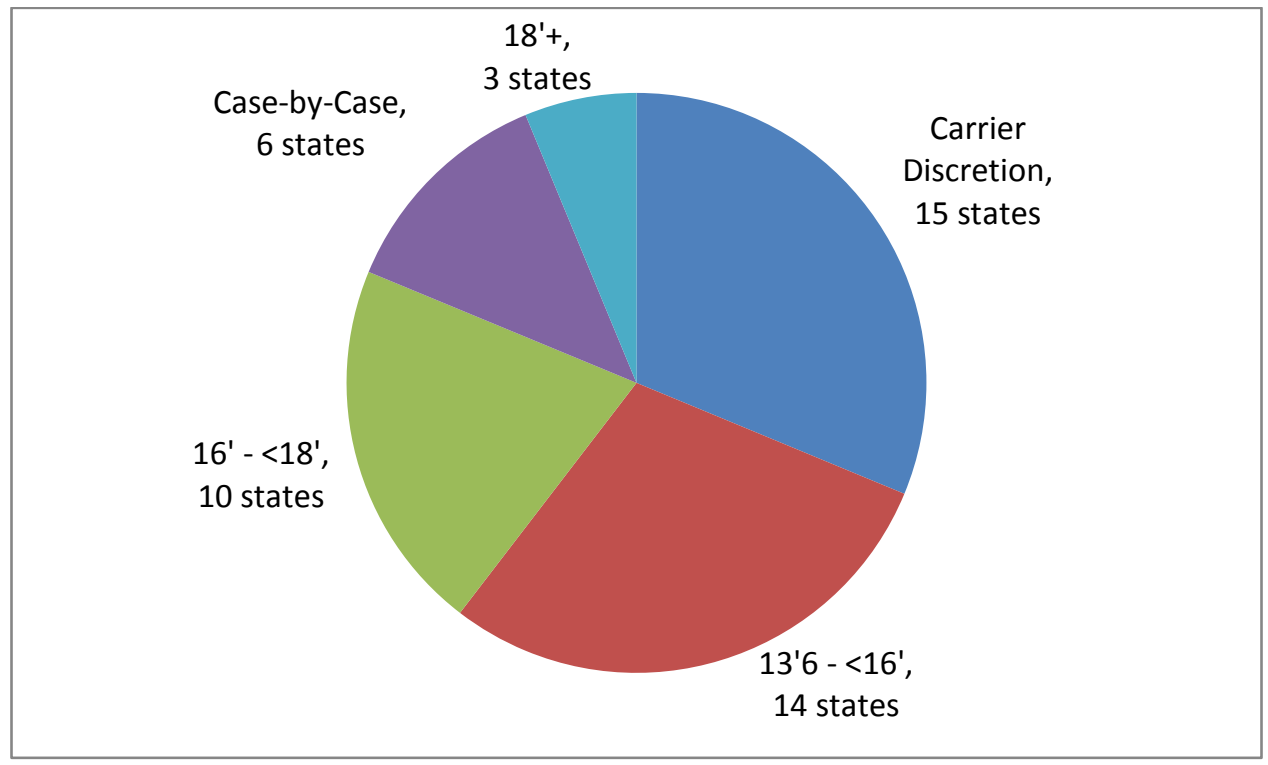

Figure 6. Variation in state route survey requirements based on height

In addition to these route survey requirements, 30 states require permittees to notify utilities if their load exceeds certain height requirements, most commonly when a load exceeds 17 feet. 


\subsection{Escort Vehicle Requirements}

Even with an approved route, many states require an escort vehicle for OSOW loads to ensure more efficient and safe travel through the state. For example, all Lower 48 states require at least one escort vehicle for loads that exceed width thresholds. Fewer states (42) require an escort vehicle for loads that exceed height requirements. Of these 42 states, 36 require at least one escort vehicle to be a pilot car.

In some cases, states require at least one of the escort vehicles be driven by law enforcement personnel. This is most common in the case of over-width loads and least common in the case of overweight loads (Figure 7). In cases where a civilian escort vehicle is allowed, 12 states require civilian drivers to carry certification.

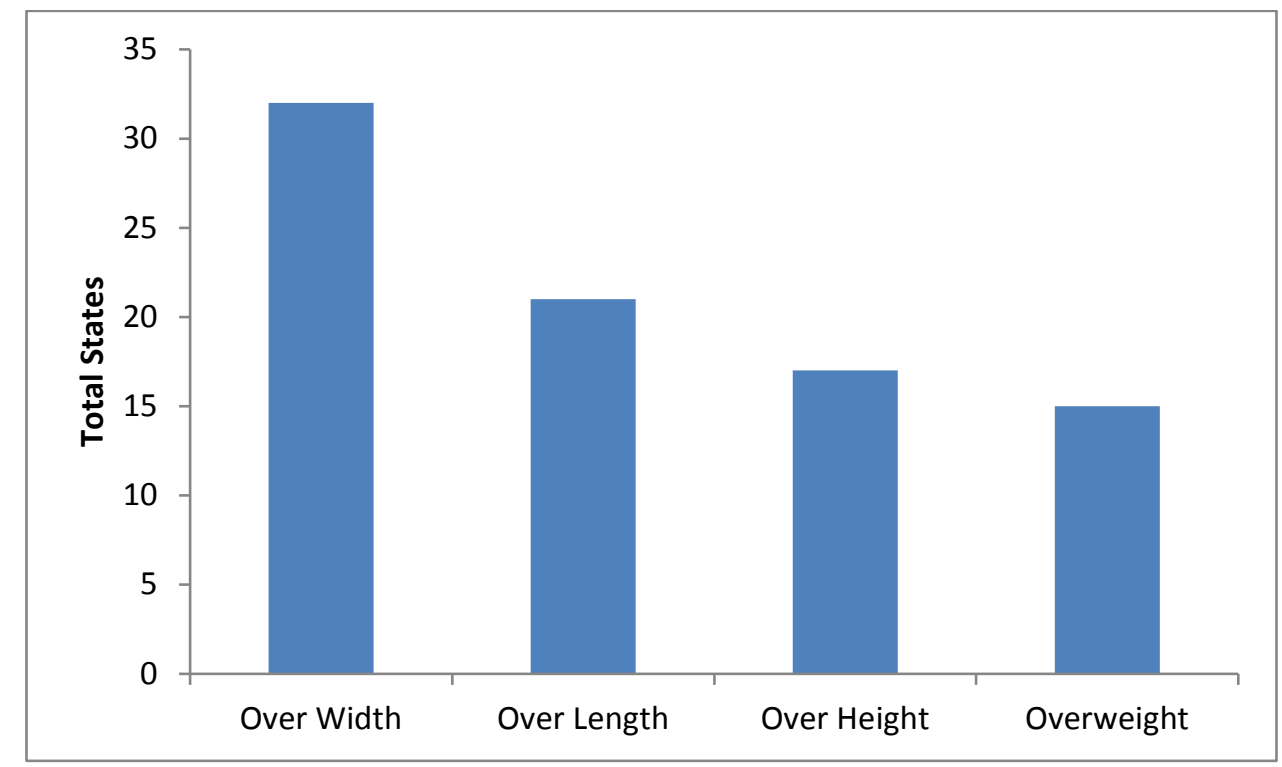

Figure 7. Number of states that may require at least one law enforcement escort for certain OSOW loads

\subsection{Weekday and Weekend Travel Requirements}

Regulated loads often face certain travel time restrictions based on the day of the week. Such restrictions vary by the dimensions and weight of the load (Figure 8). For example, the majority of states (34) allow at least some overweight vehicles to travel 24 hours per day during weekdays, while the remaining 14 states have at least some weekday travel restrictions. In comparison, only 15 states allow at least some over-height vehicles to travel 24 hours per day during weekdays. 


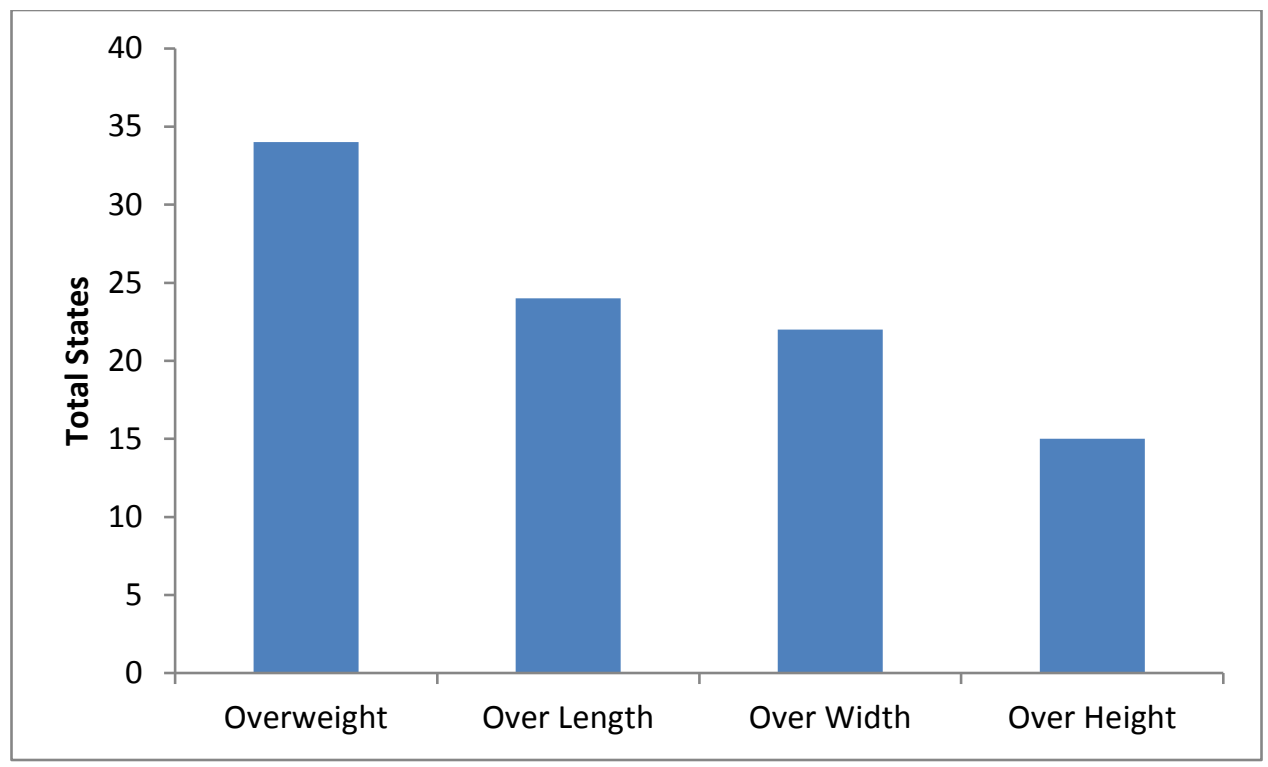

Figure 8. Number of states that allow 24-hour weekday travel for at least some OSOW loads

In most states, travel requirements are different on weekends, again by day. Three states either prohibit Saturday travel (New Hampshire and Rhode Island) or impose summer restrictions (Maine), while 10 states do the same for Sundays. As was the case with weekday travel, there is variation across the states in those that allow 24-hour weekend travel (Figure 9). Again, more states are likely to allow overweight vehicles to travel 24 hours per day on weekends, while this is less likely for over-height vehicles.

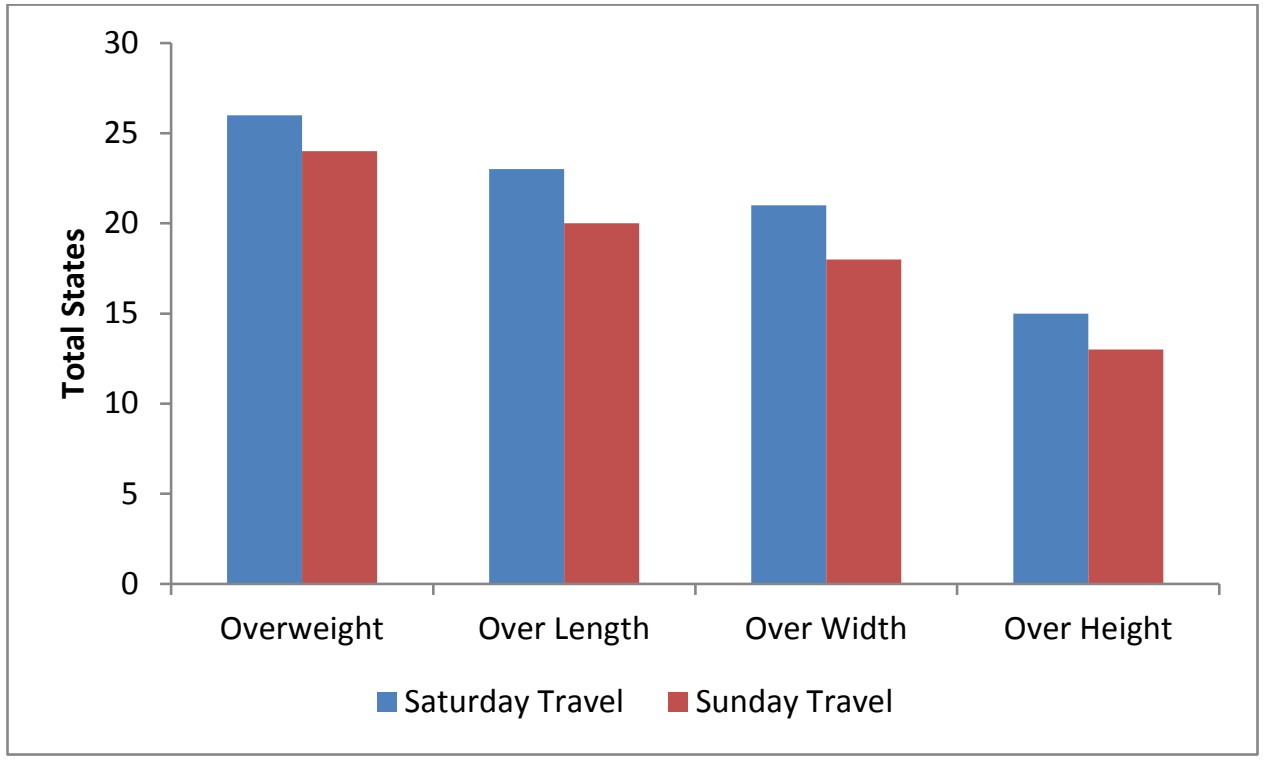

Figure 9. Number of states that allow 24-hour weekend travel for at least some OSOW loads 


\section{Issues and Hurdles}

The variations in regulation of OSOW loads can make it difficult for carriers to efficiently move OSOW loads across state lines or even within a state. The issues with transporting wind components in particular were highlighted in a webinar hosted by NREL with regulators and industry personnel on February 24, 2016. This section summarizes the hurdles to efficient transport of wind components that were most frequently referenced in the webinar.

\subsection{Inconsistency in State Regulatory Requirements}

Differences in regulatory requirements as they relate to dimensions, weight, and vehicle escorts were all cited as problematic for transporting wind components across state lines. These problems largely stem from the issue that a carrier may have to comply with certain OSOW load requirements in one state that are then unnecessary in another state.

A travel scenario outlined by Mooney and Maclaurin (2016, p. 22) in which a hypothetical carrier travels from Massachusetts to Michigan through New York, Pennsylvania, and Ohio is a useful illustration to demonstrate some of these hurdles. For example, if a carrier is transporting a section of a wind tower across these states, it may qualify as an OSOW load based on its width in Michigan, New York, and Pennsylvania but not in Ohio or Massachusetts.

These distinctions are important because they influence the number of escort vehicles required as well as the requirements in other regulations. For example, the wind tower may need a law enforcement escort on two-lane roads in New York, and Pennsylvania but not in Ohio or Michigan. ${ }^{4}$ Whether escort vehicles are required on multilane roads - and if so, how many are required - also varies across the states. For example, as many as three escort vehicles may be required on multilane roads in Massachusetts and only two are required in Ohio, Michigan, and New York.

One industry representative participating in the webinar stated this variation across states can increase costs, "knowing the costs from state to state is key." Determining these costs is challenging, given the significant differences in regulations from state to state, and industry participants in the webinar called for greater consistency in regulations to help manage costs.

\subsection{Coordination of Interstate Travel}

Due to the variation in OSOW load designations and associated requirements, a carrier of wind components cannot apply for a universal permit that allows a load to travel across the country. Rather, a carrier may be required to file a permit application in each of the states they travel. Industry participants in the webinar noted this arrangement can cause the volume of required permits to go up dramatically depending on the states that fall within the preferred transportation route.

\footnotetext{
${ }^{4}$ It is possible that in some states such as Iowa, these personnel must be on-duty, provided stopping traffic along the route is necessary. Or, an on-duty officer must be contacted to carry out necessary traffic stops. See IAC (2012).
} 
Industry representatives and regulators also noted that in some cases permitting authorities in one state do not coordinate with permitting authorities in other states. For example, one regulator noted that they "have not reached out to other states extensively," leaving carriers to handle that work. One regulator went further and suggested it is difficult for them to plan for efficient OSOW travel when they have entities from outside their state attempting to use their roadways. Simply put, it is difficult for regulators to plan for all the possible loads that may wish to travel through a state to reach their destination. Industry representatives went on to suggest some states act as "barrier states" and are not helpful in ensuring the efficient travel of wind components across their state or other states.

This lack of coordination among industry and permitting authorities makes it more difficult for industry to efficiently plan transportation for wind components, potentially causing project delays via increased permit application and processing times as well as routing changes.

\subsection{Coordination of Intrastate Travel}

Although interstate travel issues were more prevalent during the webinar, both industry representatives and regulators suggested that the role of local jurisdictions in intrastate travel also presents challenges to transporting wind components. One regulator said their state struggles "to determine what needs to be done for counties and localities" to ensure wind components can travel on highways under local jurisdiction. This is important because another regulator said these local governments could prohibit travel of OSOW loads on the highways under their jurisdiction if they choose to do so. ${ }^{5}$ Thus, for any given project, 5 to 17 entities within the same state might have to approve or at least agree about the proposed route, according to one webinar participant.

In some cases, regulators expect industry to be heavily involved in making the proper contacts at the local level and anticipating problems, while in other instances regulators support the industry in these logistics discussions. Regardless, making these contacts and receiving approval from local jurisdictions may cause delay associated with permitting approval processes and making route accommodations.

\subsection{Permit Delays and Complications Associated with Route Development and Changes}

All of the aforementioned issues make it difficult to develop a transportation route for wind components within and across states. Even in those cases where a state or states have strong working relationships and largely consistent regulations, identifying a route for each particular project remains a challenge. One regulator concluded, "the number one delay is caused by being able to find a viable route."

Route development can be even more time consuming in those states where a new route must be developed each time, even if a carrier has experience transporting components across a specified route. For example, one industry representative mentioned that in some states it is not possible to receive "cloner" permits to streamline the permitting process associated with transporting multiple components related to a given project. In addition, industry personnel suggested that

\footnotetext{
${ }^{5}$ For example, in Wisconsin, town governments have the authority over "town highways" as outlined in Chapter 82.03 of Wisconsin state statute available here: https://docs.legis.wisconsin.gov/statutes/statutes/82.
} 
some states do not have robust pre-approval processes by which a carrier can work on applications in advance of transporting their load.

Regulators noted that even in cases where a viable or pre-approved route might exist, keeping that path open during the life of the project is difficult. For example, construction often closes viable paths. One regulator said that "even with your best efforts you have construction and that can cause delays." An industry representative noted that in some cases they do not realize a route is not viable due to construction until encountering that construction on the route. This participant said that having a "better idea of when construction is going to start or when a delay might happen can get us out in front of it looking for alternative route options." Even with advanced notice, identifying a second route also takes time, and one regulator noted that in some cases an alternative route might not exist. 


\section{Best Practices}

Given the issues and hurdles outlined in the previous section, industry and the states have developed best practices to more efficiently transport wind turbine components from manufacturers to project locations. These practices range from infrastructure improvements to the development of a pre-approval permit process.

\subsection{Infrastructure Improvements}

Some states have worked closely with industry and invested significantly in road infrastructure improvements to more efficiently transport wind turbine components within their respective states. For example, since 2011, the Wisconsin Department of Transportation (WisDOT) has been working with Broadwind Energy, a wind turbine manufacturer located in the state, to identify and address barriers to efficient travel (WisDOT 2015).

Traffic delays associated with making turns to enter and exit highways was one problem these entities identified and resolved so that carriers were no longer required to stop traffic or be accompanied by law enforcement escorts. One participant in the webinar suggested that this and other infrastructure improvements amounted to over \$2 million dollars in investment. WisDOT suggests that these improvements have allowed the manufacturer to increase production as a result (WisDOT 2015).

\section{Caution}

Though this type of direct investment can have significant impacts on increasing the efficiency of wind component travel within a state, this approach may not be feasible or practical in all states. For states with large wind turbine manufacturing facilities, this approach may be attractive to support this industry in their states. ${ }^{6}$ In contrast, states that are along a route or are end users of the wind components being transported may be less willing or unable to make these investments since much of the benefit in terms of cost savings may leave the state.

\subsection{Regional Permitting Arrangements}

Thirty-two of the Lower 48 states are members of regional permit agreements; these range from bilateral agreements to 16 -state regional agreements (Figure 10). ${ }^{7}$ Despite this variation, the goal of these agreements is to streamline permitting processes for OSOW loads across the participating states by issuing joint or comprehensive permits across the participating states.

\footnotetext{
${ }^{6}$ The American Wind Energy Association (AWEA) tracks over 500 wind turbine component manufacturers in the United States across 43 states. Twenty-one of these facilities, spread across 15 states, build utility-scale blades, towers, and nacelles. See AWEA (n. d.).

${ }^{7}$ Alabama, Louisiana, Ohio, Oklahoma, Texas, and West Virginia along with 10 other southern states participate in the largest regional agreement that grants each state the authority to issue the Southern Regional Permit.
} 


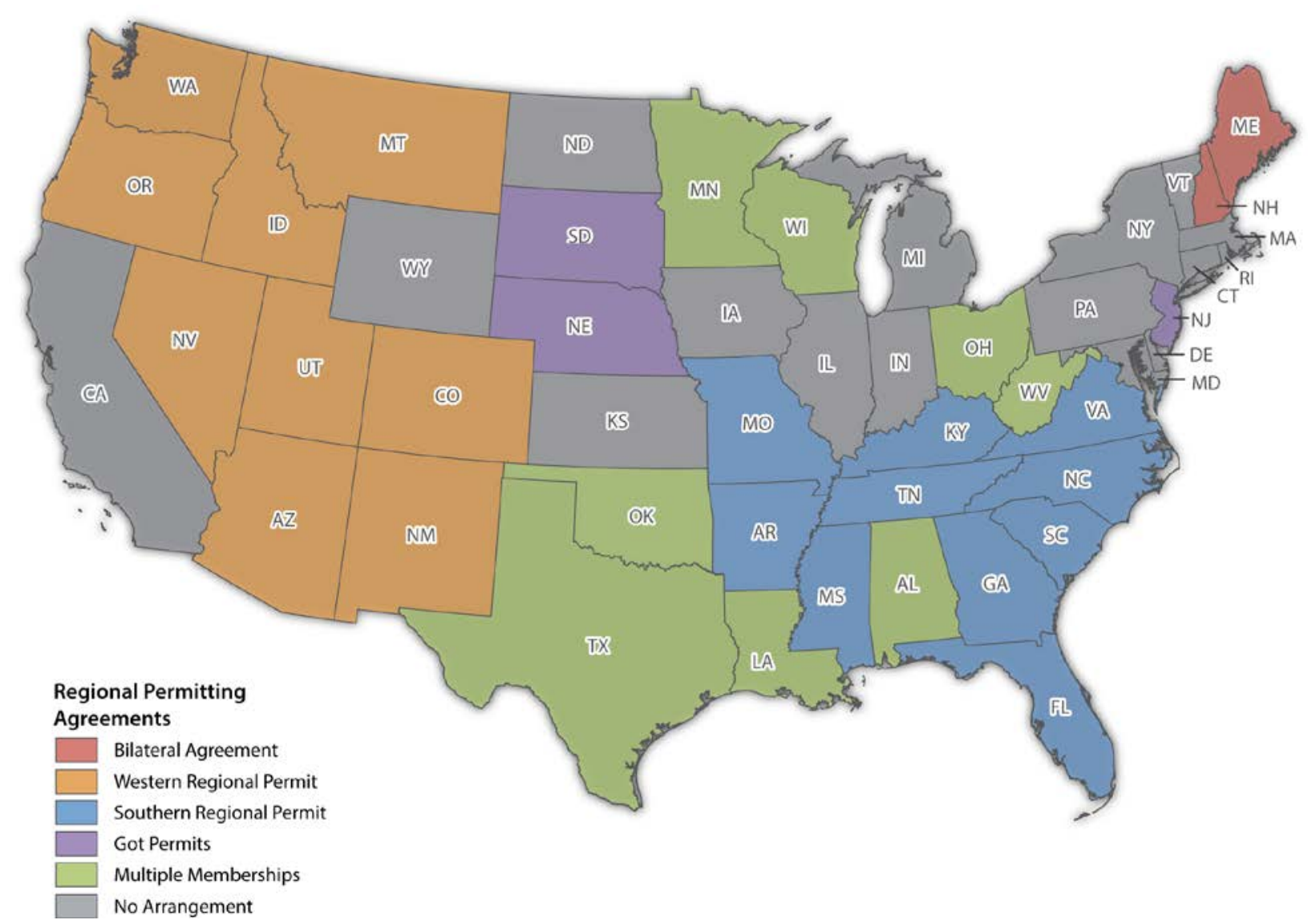

Figure 10. States that participate in a regional permitting agreement

Two pairs of states (Minnesota and Wisconsin, and Maine and New Hampshire) have bilateral agreements directed at serving this goal. One regulator noted that Minnesota and Wisconsin developed their agreement after "it became clear that $22 \%$ of all single-use permits in either state" crossed the border. As an effort to streamline costs associated with permitting these loads, these states signed a memorandum of understanding to issue permits "to the greatest extent possible....as if they didn't have a border." In line with the memorandum, they developed a joint "WINNDOT" cross-border permit portal to manage the transport of OSOW loads across the states' border. ${ }^{8}$ In the case of Maine and New Hampshire, these two states originally were a part of a larger regional group still referred to as the New England Transportation Consortium that operates currently as a bilateral agreement that is similar to that of Wisconsin and Minnesota (GAO 2015). ${ }^{9}$

In comparison, three large regional agreements include the Western Regional Permit, the Southern Regional Permit, and Got Permits (GAO 2015). Across these larger regional permit arrangements, one state can issue a single-trip permit that applies to all states that are a party to

\footnotetext{
${ }^{8}$ For more information about the portal, see http://wisconsindot.gov/Pages/dmv/com-drv-vehs/mtr-cartrkr/WINNDOT-permit.aspx.

${ }^{9}$ Massachusetts left the New England Transportation Consortium (NETC) due to a change in regulations and the limited authorized routes available through the NETC states. See http://www.nh.gov/dot/org/operations/highwaymaintenance/overhaul/documents/MassNoticeConsortiumPermits11-1-13Discontinued2.pdf
} 
the given agreement. ${ }^{10}$ One regulator with experience issuing the Western Regional Permit, which was developed by the Western Association of State Highway and Transportation Officials, ${ }^{11}$ said that, "if the carrier is starting in your state, you can issue a permit for your state and the other [participating] states... we develop a route based upon the approved routes in the middle states and then call the last state to get the final route. We then charge the permit fees for each state."

Though they are useful, these regional permits are not universal, and as one regulator said, "we'll get [the carriers] as far as we can... but it is up to the carrier to handle the rest." At the present, 16 states do not participate in a regional permitting agreement and carriers have to work with these individual states if they have jurisdiction over highways on the preferred route (Figure 10).

One industry participant said, "there are some states that won't participate," suggesting there are limits to further regional permit adoption. Outside of states formally joining these regional arrangements, one regulator said this is a "relationship business" and just building "good working relationships with border states" can streamline interstate permitting processes.

\section{Caution}

Noteworthy participants did not universally consider developing a nationally harmonized permitting system as feasible at this time. One regulator considered this a daunting task and argued that a focus on further regional harmonization was a better approach. Another participant argued that a one-size-fits-all approach would not work because of differing geographies such as those of the adjoining Great Plains and mountain states. Additional barriers may include variation in the age and design of infrastructure, along with the presence of large metropolitan areas and roads with frequent curves. Regardless, one industry participant did note that their long-term goal continued to be a nationally harmonized permitting process.

\subsection{Online Permitting Systems}

Currently, 43 states have online permitting systems (GAO 2015). ${ }^{12}$ A range of third parties and individual states have developed these online permitting systems to reduce permitting application and processing times. One regulator said it seems these "automated systems can work and seem to be taking over." Another regulator elaborated on the value of these systems, arguing their online system has streamlined their processes because " $60 \%$ of permits issued we never see and it's handled automatically. This allows us to free up staff for those carriers or individuals that need some help navigating the process or understanding the requirements."

Online permitting systems are not always standardized. For example, permits can be issued automatically in some states but not in others (GAO 2015). Regardless, one regulator said having an online system allows for "additional staff to work on the permits and approvals that cannot be done automatically, especially stuff in the super load area [i.e., OSOW] or extremely large components like you find with wind turbines." Thus, these online permitting processes may be

\footnotetext{
${ }^{10}$ The Western Regional Permit can apply to vehicles with loads less than 160,000 pounds, while the Southern Regional Permit can apply to those under 120,000 pounds (GAO 2015).

${ }^{11}$ See http://www.washto.org/.

12 Nevada, Oregon, Tennessee, Vermont, and Wyoming do not have online permitting systems.
} 
one pathway to reduce permit processing times, even if wind component carriers cannot use them to issue permits for their loads.

The New York Department of Transportation Highway Oversize/Overweight Credentialing System (HOOCS) is one example of an online permitting system currently in development. HOOCS, like many other state online permitting systems, will allow carriers to auto-issue certain OSOW permits $24 / 7$ without permit office intervention. It uses a geographic information system (GIS) to generate approved routes for trip permits using New York State-owned GIS data. However, unlike many other online permit systems, HOOCS will allow the New York State Department of Transportation to issue permits in partnership with "integrated permitting agencies," such as municipal governments, bridge agencies, and even neighboring states. Using HOOCS, these integrated permitting agencies will be able to identify and add road restrictions for their jurisdiction (both temporary and permanent), verify and update any missing GIS data, and participate in route-tuning sessions. HOOCS will effectively create a "one-stop shop" for travel through New York and bordering states whereby carriers can apply through the system and each applicable permitting authority can independently approve their permit in HOOCS and generate an approved route.

\section{Caution}

Given that a variety of entities developed these online permitting systems, they are not structured or designed in the same way. This can limit the ability for these systems to interact with, or be used in conjunction with each other. This may be especially problematic for carriers transporting loads outside states that are party to regional permit agreements. In addition, there is some concern that allowing carriers to "self-issue" a permit online may entail safety risks. For example, the National Traffic Safety Board (NTSB 2014) noted this approach does not "motivate carriers to conduct route surveys before transporting oversize loads."

\subsection{Alternative Routes}

Delays caused by the need to develop a new route for an OSOW load permit was one of the most common themes during our discussion with industry and regulators. One regulator stated that in their state, individual permits are only good for five to seven days. The regulator elaborated that they try to keep an overarching route open for the entire project, but if this becomes unviable, they have to develop a new route and survey it. One way to alleviate some of these delays is to develop an alternative route (when possible). As one industry participant stated, the alternative route takes upfront time to develop but provides a "just in case" to help keep the project on schedule.

\section{Caution}

An alternative route may not always be available for a particular OSOW load. Even when an alternative route is available, additional planning and surveying are required before issuance of the permit.

\subsection{Pre-approval Permits}

Certain states require carriers to complete the entire permitting process and pay a fee for every single-trip permit, even if the OSOW load is virtually identical to other loads the carrier is transporting along the same route. One industry participant noted that navigating the entire 
permitting process and gaining approval can take several days to weeks for each individual move. Also, approval of a permit may be delayed when regulators are out of the office or when the permit office experiences an increase in workload. Some regulators participating in the webinar stated that individual single-trip permits had replaced "blanket" permits, which allowed for multiple trips on a single approval, because the state could not recoup the cost of processing the blanket permit at the charged flat fee due to the number of trips that occur under a blanket permit.

Other states allow carriers to apply for a permit pre-approval, where the carrier indicates the number of loads that it will make over a specified period (e.g., 20-60 days) from the date of the pre-approval. The pre-approval then allows a carrier to purchase single-trip permits when needed during this period, and carriers can have the permit within one to two hours. One industry participant noted that this process significantly reduces the amount of delays for carriers as well as the workload for the permit office while still paying a fee for each single-trip permit.

\section{Caution}

As discussed above, the need to develop an alternative route due to road closures, construction, or other issues that interfere with the viability of the planned route may at times limit the usefulness of a pre-approval permit. This is specifically the case where the pre-approval permit does not include an alternative route. 


\section{Future Analysis and Facilitation}

The analysis funded under this scope of work focused on the current state of regulations for OSOW loads, the issues and hurdles for transporting large wind components, and observed best practices. To fully understand the scope of impacts on wind component transportation under the current regulatory environment would require time delay and cost analysis. Time delay analysis could focus on time variations between different regulatory approaches employed by individual states as well as the multi-state approaches. In addition, cost analysis could focus on costs for different state-level regulatory approaches as well as the costs associated with having to comply with multiple regulatory approaches when transporting loads between states.

Facilitation of meetings for AWEA, the Specialized Carriers and Rigging Association, the American Association of State Highway and Transportation Officials, and other entities involved in regional and national regulatory harmonization efforts for OSOW loads may provide additional insight into advantages and challenges associated with regulatory harmonization. Facilitation can support harmonization efforts only if the appropriate stakeholders are willing and able to reach common ground to address time delays and additional costs associated with a statespecific regulatory approach. 


\section{Conclusion}

Regulatory and permitting issues surrounding the transportation of OSOW wind components continue to be a major point of discussion among industry stakeholders and regulators. Many states have taken efforts to streamline the permitting process within their states. Efforts to expedite the permitting process have included infrastructure improvements, regional permitting agreements, online permitting systems, alternative routes, and pre-approval permits.

Carriers transporting wind components in both intrastate and interstate travel continue to face issues surrounding inconsistent regulations from jurisdiction to jurisdiction. While many states have made efforts to form bilateral or regional partnerships to allow carriers to use pre-defined or coordinated routes through groups of states, a national harmonization effort to create uniform regulations and nationwide permits has largely failed to gain traction among the Lower 48 states. Many states believe that regional diversity among the states prevents a uniform set of national regulations. However, industry and regulatory associations, including the American Association of State Highway and Transportation Officials and the Specialized Carriers and Rigging Association continue to discuss the possibility of national harmonization. 


\section{References}

AWEA (American Wind Energy Association). n.d. "Manufacturing: Overview." Washington, D.C.: AWEA.

http://www.awea.org/gencontentv2.aspx?ItemNumber=5081\&mainnav=8192\&navItemNumber= $\underline{8211 .}$.

DOE (U.S. Department of Energy). 2015. Quadrennial Energy Review: Energy Transmission, Storage, and Distribution Infrastructure. DOE. April 2015.

http://energy.gov/sites/prod/files/2015/07/f24/

QER\%20Full\%20Report TS\%26D\%20April\%202015 0.pdf.

GAO (U. S. Government Accountability Office). 2015. Transportation Safety: Federal Highway Administration Should Conduct Research to Determine Best Practices in Permitting Oversize Vehicles. U. S. Government Accountability Office. GAO-15-236.

http://www.gao.gov/assets/670/668711.pdf.

IAC (Iowa Administrative Code). 2012. Chapter 511: Special Permits for Operation and Movement of Vehicles and Loads of Excess Size and Weight. May 30. 2012.

https://www.legis.iowa.gov/docs/ACO/chapter/761.511.pdf.

Mooney, Meghan, and Galen Maclaurin. 2016. Evaluation of Logistical and Infrastructure Requirements for Transporting Large Wind Energy Components: Spatial Data. Golden, CO: National Renewable Energy Laboratory. NREL/TP-6A20-67014.

NTSB (National Traffic Safety Board). 2014. Highway Accident Report: Collapse of the Interstate 5 Skagit River Bridge Following a Strike by an Oversize Combination Vehicle: Mount Vernon, Washington: May 23, 2013. Washington, D.C.: National Traffic Safety Board. NTSB/HAR-14/01, PB2014-106399. http://www.ntsb.gov/investigations/AccidentReports/ Reports/HAR1401.pdf.

WisDOT (Wisconsin Department of Transportation). 2015. "Recent Highway Improvements in Wisconsin have Boosted Traffic Safety while Eliminating the Need for State Patrol Escorts." Wisconsin Traffic Safety Reporter 18(3):9-10.

Zayas, Jose, Michael Derby, Patrick Gilman, Shreyas Ananthan, Eric Lantz, Jason Cotrell, Fredric Beck, and Richard Tusing. 2015. Enabling Wind Power Nationwide. U.S. Department of Energy. May 2015. DOE/EE-1218. http://energy.gov/sites/prod/files/2015/05/f22/EnablingWind-Power-Nationwide 18MAY2015 FINAL.pdf. 